\title{
Changes in the microbial consortium during dark hydrogen fermentation in a bioelectrochemical system increases methane production during a two-stage process
}

Kengo Sasaki ${ }^{1}$, Daisuke Sasaki ${ }^{1}$, Yota Tsuge ${ }^{2}$, Masahiko Morita ${ }^{3}$ and Akihiko Kondo ${ }^{1,4^{*}}$

\begin{abstract}
Background: Bioelectrochemical systems (BESs) are an innovative technology developed to influence conventional anaerobic digestion. We examined the feasibility of applying a BES to dark hydrogen fermentation and its effects on a two-stage fermentation process comprising hydrogen and methane production. The BES used low-cost, low-reactivity carbon sheets as the cathode and anode, and the cathodic potential was controlled at $-1.0 \mathrm{~V}(\mathrm{vs}$. Ag/AgCl) with a potentiostat. The operation used $10 \mathrm{~g} / \mathrm{L}$ glucose as the major carbon source.

Results: The electric current density was low throughout $\left(0.30-0.88 \mathrm{~A} / \mathrm{m}^{2}\right.$ per electrode corresponding to $0.5-$ $1.5 \mathrm{mM} /$ day of hydrogen production) and water electrolysis was prevented. At a hydraulic retention time of 2 days with a substrate $\mathrm{pH}$ of 6.5 , the BES decreased gas production (hydrogen and carbon dioxide contents: 52.1 and $47.1 \%$, respectively), compared to the non-bioelectrochemical system (NBES), although they had similar gas compositions. In addition, a methane fermenter (MF) was applied after the BES, which increased gas production (methane and carbon dioxide contents: 85.1 and 14.9\%, respectively) compared to the case when the MF was applied after the NBES. Meta $16 \mathrm{~S}$ rRNA sequencing revealed that the BES accelerated the growth of Ruminococcus sp. and Veillonellaceae sp. and decreased Clostridium sp. and Thermoanaerobacterium sp., resulting in increased propionate and ethanol generation and decreased butyrate generation; however, unknowingly, acetate generation was increased in the BES.
\end{abstract}

Conclusions: The altered redox potential in the BES likely transformed the structure of the microbial consortium and metabolic pattern to increase methane production and decrease carbon dioxide production in the two-stage process. This study showed the utility of the BES to act on the microbial consortium, resulting in improved gas production from carbohydrate compounds.

Keywords: Bioelectrochemical system, Dark fermentation, Hydrogen, Methane, Microbial consortium, Two-stage process

\footnotetext{
*Correspondence: akondo@kobe-u.ac.jp

${ }^{1}$ Graduate School of Science, Technology and Innovation, Kobe

University, 1-1 Rokkodaicho, Nada-ku, Kobe, Hyogo 657-8501, Japan

Full list of author information is available at the end of the article
} 


\section{Background}

Bioelectrochemical systems (BESs) are a novel technology based on both biological and electrochemical processes for the production of valuable products from waste and wastewater [1-3]. BESs consist of an anode and cathode, and can change microbial fermentation by overcoming the thermodynamic limits of metabolic routes [4]. Anaerobic digestion is a classic method of degrading complex molecules such as waste materials into methane and carbon dioxide via a mixed microbial consortium [5, 6], which offers benefits such as the lack of need for sterilisation for microbial processing of waste streams and resilience to adverse conditions [5]. BESs have been used in anaerobic digestion of organic matter to influence the structure and/or metabolism of the microbial consortium and boost hydrogen production [7], methane production [8-10], and biohythane production [11].

Gaseous fuels such as hydrogen and methane, which can be used in heat and/or electricity production and for transport, are often obtained via two-stage fermentation $[12,13]$. In the first stage, organic matter in the substrate is degraded to release hydrogen during dark fermentation. In the second stage, residual carbohydrates such as volatile fatty acids and alcohols are further converted into methane. Compared with single-stage methane fermentation, the two-stage fermentation process has advantages of high energy production, a high organic loading rate (OLR), and a stable process for optimising process parameters and breaking down inhibitors in the first stage [12]. We previously used a BES to apply a potential in hydrogen fermentation [7]. The configuration of this system was similar to that of a single-chamber microbial electrolysis cell (MEC) without a membrane [14]. However, it differed in the following ways. Our BES used low-cost carbon sheets (graphite blocks) as the working and counter electrodes and a high anode potential (e.g., $1.61 \mathrm{~V}$ vs. $\mathrm{Ag} / \mathrm{AgCl}$ ) was produced using a potentiostat to inhibit methanogenic activity and prevent hydrogen consumption [15]. Moreover, our BES enabled hydrogen fermentation from artificial garbage slurry at relatively high $\mathrm{pH}$ conditions of 5.5-7.2 [7]. In general, the $\mathrm{pH}$ during dark hydrogen fermentation is 5.0-7.0; however, relatively high $\mathrm{pH}$ conditions are favoured to prevent accidental decreases in hydrogen production due to the accumulation of by-products (i.e., acids) and a decreased $\mathrm{pH}$ [16]. Regardless, the detailed effects of a BES on polarising electrodes in the microbial consortium in hydrogen fermentation are unclear. However, the effects of a BES on the microbial consortium in other environments (e.g., methane fermentation) have been investigated, and it has been shown to activate methanogenic archaea and/or enhance direct interspecies electron transfer between microorganisms, increasing methane generation [10, 17]. In addition, research on the twostage approach involving bioelectrochemical hydrogen fermentation and methane fermentation is limited [7].

The aim of this study is to investigate the effects of a $\mathrm{BES}$ for polarising electrodes on the microbial consortium in the first stage of fermentation (i.e., hydrogen fermentation) at a $\mathrm{pH}$ greater than 6.0 using glucose as the model organic substrate. Next-generation sequencing was employed to characterise the change in the composition of the microbial consortium after the use of the $\mathrm{BES}$. In the second stage, a methane fermenter (MF) was applied and its effects were evaluated using a packed-bed reactor containing carbon fibre textiles (CFTs) as supporting material for retaining microorganisms, because packed-bed systems are capable of increasing the OLR and methanogenesis [18].

\section{Methods}

\section{Configuration and operation of the BES for hydrogen fermentation}

For the first stage of hydrogen fermentation, an H-type two glass reactor (working volume of each reactor: $250 \mathrm{~mL}$; total working volume: $500 \mathrm{~mL}$ ) for the BES was constructed, as described previously [7]. Both the working electrode (cathode) and counter electrode (anode) were composed of carbon sheets (graphite blocks with dimensions of $25 \times 75 \times 2 \mathrm{~mm}$ ) (Fig. 1a). $\mathrm{An} \mathrm{Ag} / \mathrm{AgCl}$ reference electrode (saturated $\mathrm{KCl}$ ) was inserted in the cathodic working side. All potentials reported here are with respect to that of the $\mathrm{Ag} / \mathrm{AgCl}$ reference electrode (199 $\mathrm{mV}$ vs. that of a standard hydrogen electrode). The potential of the working electrode was electrochemically regulated to $-1.0 \mathrm{~V}$ (vs. $\mathrm{Ag} / \mathrm{AgCl}$ ) using a potentiostat (PS-08; Tohogiken, Japan). Then, $500 \mathrm{~mL}$ of sludge from the methane fermenter $\left(55^{\circ} \mathrm{C}\right)$ to degrade $1 \%$ glucose was used to inoculate the BES. Each glass reactor had two medium/sludge sampling ports and one gas outlet port connected to a gas sampling collection bag. One glass reactor without an electrode $(250 \mathrm{~mL})$ was used as the control [described as a non-bioelectrochemical system (NBES)]. As described above, $250 \mathrm{~mL}$ of sludge was used to inoculate the NBES. The contents of both the cathodic working side and anodic counter side in the BES and NBES were mixed thoroughly using a magnetic stirrer. The temperature of the culture was maintained at $55^{\circ} \mathrm{C}$. The operation was performed in duplicate.

The BES and NBES were fed with an artificial medium. The medium (per liter) was composed of glucose: $10 \mathrm{~g}, \mathrm{KH}_{2} \mathrm{PO}_{4}: 0.1 \mathrm{~g}, \mathrm{~K}_{2} \mathrm{HPO}_{4}: 0.2$ g, yeast extract: $1 \mathrm{~g}, \mathrm{NaHCO}_{3}: 2 \mathrm{~g}, \mathrm{NH}_{4} \mathrm{Cl}: 1 \mathrm{~g}, \mathrm{MgCl}_{2} \cdot 6 \mathrm{H}_{2} \mathrm{O}: 0.1 \mathrm{~g}$, $\mathrm{CaCl}_{2} \cdot 2 \mathrm{H}_{2} \mathrm{O}: 0.1 \mathrm{~g}, \mathrm{NaCl}: 0.6 \mathrm{~g}$, trace element solution (Deutsche Sammlung von Mikroorganismen und Zellkulturen [DSMZ] 141 medium): $10 \mathrm{~mL}$, and vitamin 


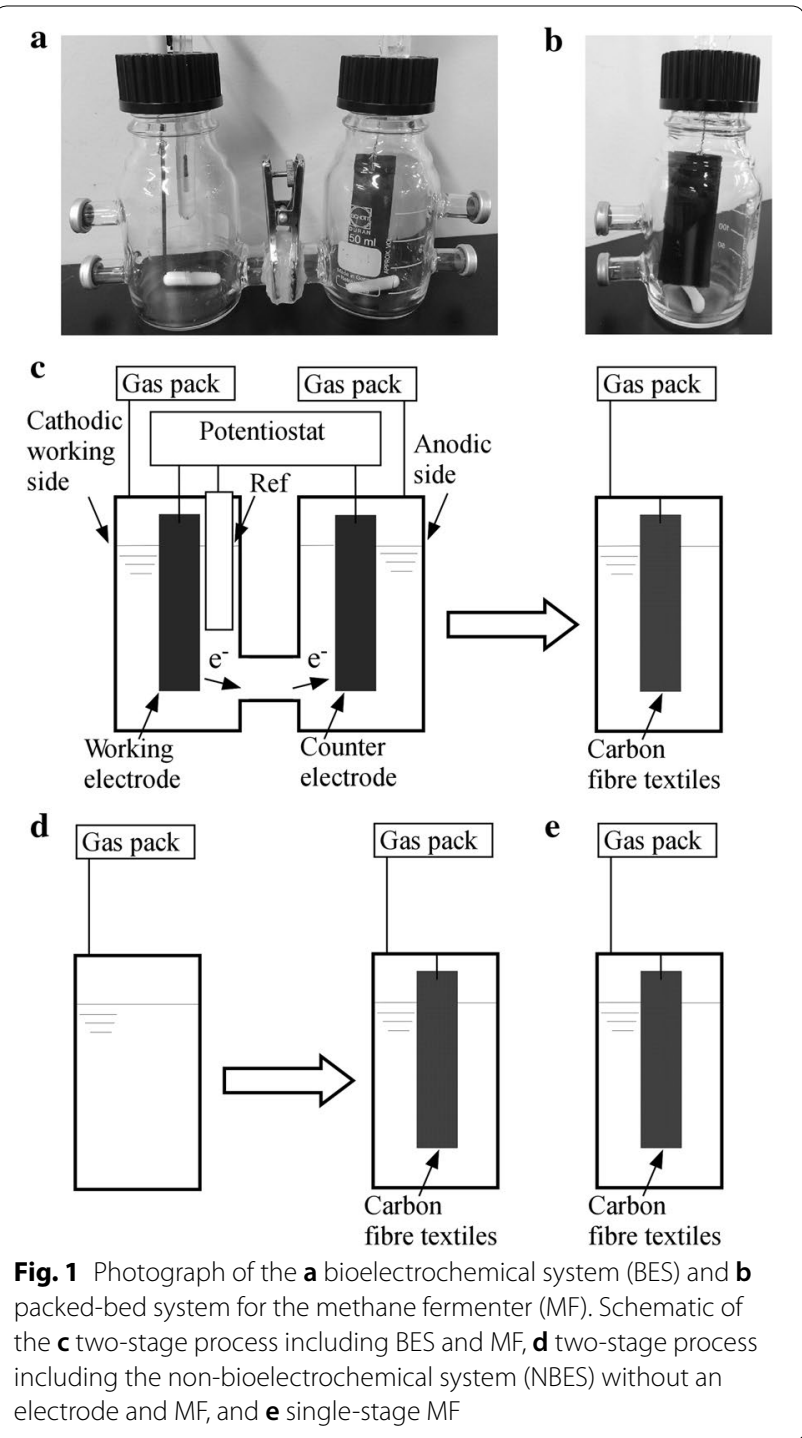

solution (DSMZ 141 medium): $1 \mathrm{~mL}$. Once per day, a predetermined volume of the fermentation liquid on both the cathodic and anodic sides of the BES and control reactor was discharged and the same volume of fresh artificial medium was added. The hydraulic retention time (HRT) was 2 or 4 days, meaning that half or onefourth of the fermentation liquid was exchanged daily.

\section{Configuration and operation of the pecked-bed reactor for methane fermentation}

One glass reactor $(250 \mathrm{~mL})$ was used for the second stage of methane fermentation (Fig. 1b). Each glass reactor was packed with two sheets of CFT (type: pitch; porosity: 98\%; diameter: $25.0 \mathrm{~mm}$; height: $70.0 \mathrm{~mm}$; thickness: $2.4 \mathrm{~mm}$ ) as support material. The inoculum and operational temperature were the same as those in the first stage. Once per day, a predetermined amount of fermentation liquid was discharged and the same volume of the effluent from the BES or NBES was added. The effluents of both the cathodic and anodic sides of the BES (total working volume of $500 \mathrm{~mL}$ ) were mixed and half of this mixture was added to the second stage (working volume of $250 \mathrm{~mL}$ ) (Fig. 1c). The effluent of the NBES was added directly to the second stage (Fig. 1d). In addition, the CFT-packed reactor was operated in a single stage of the MF by adding the above-mentioned artificial medium (Fig. 1e).

\section{Analysis of reactor performance}

The volume of gas produced was measured with a water displacement method using a graduated cylinder. The methane, carbon dioxide, and hydrogen contents of the gas were measured using a gas chromatograph equipped with a thermal conductivity detector (GC390B; GL Sciences, Tokyo, Japan) and stainless-steel column packed with active carbon (30/60 mesh; GL Sciences). The soluble total organic carbon (S-TOC) in the culture was analyzed using the $\mathrm{HACH}$ method (HACH Co., Loveland, Co., USA). The concentrations of lactate, acetate, propionate, butyrate, and ethanol were measured using high-pressure liquid chromatography (Shimadzu, Kyoto, Japan) with an Aminex HPX-87H column (Bio-Rad Laboratories, Hercules, CA, USA) and RID-10A refractive index detector (Shimadzu). The operation was performed at $65{ }^{\circ} \mathrm{C}$ using $5 \mathrm{mM} \mathrm{H}_{2} \mathrm{SO}_{4}$ as the mobile phase at a flow rate of $0.6 \mathrm{~mL} / \mathrm{min}$. The suspension was filtered through a glass fibre filter $(0.45 \mu \mathrm{m})$ to determine the cell mass in the culture, the residue on the fibre was dried at $105{ }^{\circ} \mathrm{C}$ for $120 \mathrm{~min}$, and the dry weight was measured. The carbon content in the cell mass was calculated using an empirical formula $\left(\mathrm{C}_{5} \mathrm{H}_{7} \mathrm{NO}_{2}\right)$ for a microbial cell [19].

\section{Isolation of bacterial and archaeal DNA}

Whole genomic DNA from the culture was prepared as follows. A 5000- $\mu \mathrm{L}$ aliquot of each culture was centrifuged at $5000 \times g$ and pelleted material was suspended in $200 \mu \mathrm{L}$ of Tris-EDTA buffer (10 mM Tris-HCl, $1 \mathrm{mM}$ EDTA, pH 8.0). This suspended material was transferred to a sterilised and DNA-free bead-beating tube containing $300 \mathrm{mg}$ of glass beads (diameter: $0.1 \mathrm{~mm}$ ). Approximately $500 \mu \mathrm{L}$ of Tris-EDTA-saturated phenol, $250 \mu \mathrm{L}$ of lysis buffer, and $50 \mu \mathrm{L}$ of $10 \%(\mathrm{w} / \mathrm{v})$ sodium dodecyl sulphate were added to each tube. Then, the mixture was shaken vigorously for $30 \mathrm{~s}$ at $5.0 \mathrm{~m} / \mathrm{s}$ using a FastPrep-24 instrument (MP Biomedicals, USA). Next, the mixture was centrifuged at $22,000 \times g$ for $5 \mathrm{~min}$. The upper aqueous layer was transferred to a fresh tube containing $275 \mu \mathrm{L}$ of isopropyl alcohol and a $1 / 10$ volume of $3 \mathrm{M}$ sodium acetate, and chilled at $-20^{\circ} \mathrm{C}$ for $10-15 \mathrm{~min}$. The extracted DNA precipitate was pelleted 
by centrifugation at $22,000 \times g$ for $5 \mathrm{~min}$, washed with $70 \%$ ethanol, and then dried under a vacuum. The DNA subsequently was dissolved in Tris-EDTA buffer.

\section{Illumina library generation}

The V3-V4 region of the prokaryotic 16S rRNA gene was amplified using Pro341F (5'-CCTACGGGNBGCWSCAG-3') and Pro805R (5'-GACTACNVGGGTAT CTAATCC-3') [20], where N, B, W, and V correspond to degenerate nucleotides $\mathrm{A} / \mathrm{C} / \mathrm{G} / \mathrm{T}, \mathrm{G} / \mathrm{T} / \mathrm{C}, \mathrm{A} / \mathrm{T}$, and $\mathrm{A} / \mathrm{C} / \mathrm{G}$, respectively. Illumina adapter overhang nucleotide sequences were added to the gene-specific sequences. The PCR reaction and amplicon pool preparation were performed according to the manufacturer's instructions (Illumina, San Diego, CA, USA). Each PCR reaction used $12.5 \mathrm{ng}$ of template DNA, along with $200 \mathrm{nM}$ of each primer, and $12.5 \mu \mathrm{L}$ of KAPA HiFi HotStart ReadyMix (KAPA Biosystems, Massachusetts, USA). The PCR reaction conditions were as follows: initial denaturation at $95^{\circ} \mathrm{C}$ for $3 \mathrm{~min} ; 25$ cycles at $95{ }^{\circ} \mathrm{C}$ for $30 \mathrm{~s}, 55^{\circ} \mathrm{C}$ for $30 \mathrm{~s}$, and $72{ }^{\circ} \mathrm{C}$ for $30 \mathrm{~s}$; and a final extension at $72{ }^{\circ} \mathrm{C}$ for $5 \mathrm{~min}$. The amplicons were purified using the Agencourt AMPure XP beads (Beckman Coulter, Inc., California, USA). The pooled 16S rRNA gene products $(5 \mathrm{nM})$ [along with an internal control (PhiX control V3; Illumina)] were subjected to paired-end sequencing using a MiSeq sequencer (Illumina) with a 600-cycle MiSeq reagent kit (Illumina). The PhiX sequences were removed and paired-end reads with $Q$ scores of $\geq 20$ were joined using the QIIME version 1.9.1 software package [21]. The UCLUST algorithm [22] was used to cluster filtered sequences into operational taxonomic units (OTUs) based on a 97\% similarity threshold. Chimeric sequences were detected and excluded from the library using USEARCH [22]. Representative sequences from each OTU were taxonomically classified via the GreenGenes taxonomic database using the Ribosomal Database Project (RDP) classifier [23]. The OTUs were used for alpha-diversity estimation of the ShannonWiener diversity. Principal coordinate analysis (PCoA) was conducted using OTU information from each sample and calculated based on unweighted UniFrac distances using QIIME. All raw sequence data generated in this study are stored in MG-RAST as "Two-stage hydrogen/methane fermentation process with bioelectrochemical system" under the Accession Numbers mgm4779451.3-mgm4779466.3.

\section{Results}

Inhibitory effect of electrochemical regulation on methanogenesis at a relatively low organic load

The effect of electrode polarisation on reactor performance was investigated at a relatively low OLR, $1103.8 \mathrm{mg}-\mathrm{C} / \mathrm{L} /$ day, corresponding to $13.9 \mathrm{mM}_{\text {glucose }} / \mathrm{L} /$ day, and an HRT of 4 days (Table 1). Three types of
Table 1 Operation conditions of the two-stage and singlestage fermentation process

\begin{tabular}{llll}
\hline Reactor type & $\begin{array}{l}\text { OLR } \\
\mathbf{m g - C / L / d a y ~}\end{array}$ & $\begin{array}{l}\text { HRT } \\
\text { day }\end{array}$ & $\mathbf{p H}_{\mathbf{i n}} \mathbf{p H}_{\text {out }}$ \\
\hline Two-stage & & & \\
$\mathrm{BES} \rightarrow$ MF & $1103.8 \rightarrow 793.3$ & $4 \rightarrow 4$ & $6.5,6.2 \rightarrow 6.2,7.9$ \\
$\mathrm{BES} \rightarrow$ MF & $2207.6 \rightarrow 1656.0$ & $2 \rightarrow 4$ & $6.5,6.2 \rightarrow 6.2,7.7$ \\
$\mathrm{BES} \rightarrow$ MF & $2207.6 \rightarrow 1616.3$ & $2 \rightarrow 4$ & $7.3,6.1 \rightarrow 6.1,7.7$ \\
$\mathrm{NBES} \rightarrow$ MF & $1103.8 \rightarrow 707.7$ & $4 \rightarrow 4$ & $6.5,6.5 \rightarrow 6.5,7.8$ \\
$\mathrm{NBES} \rightarrow$ MF & $2207.6 \rightarrow 1507.7$ & $2 \rightarrow 4$ & $6.5,5.9 \rightarrow 5.9,7.8$ \\
$\mathrm{NBES} \rightarrow$ MF & $2207.6 \rightarrow 1533.5$ & $2 \rightarrow 4$ & $7.3,5.7 \rightarrow 5.7,7.7$ \\
Single-stage & & & \\
MF & 1103.8 & 4 & $7.7,7.2$ \\
\hline
\end{tabular}

Two-stage process: (bioelectrochemical system (BES) $\rightarrow$ methane fermenter (MF) containing carbon fibre textiles (CFTs) or non-bioelectrochemical system (NBES) $\rightarrow$ MF containing CFTs)

Single-stage fermentation process: (MF containing CFTs)

reactors were operated, those with two-stage processes of BES $\rightarrow$ MF containing CFT and NBES $\rightarrow$ MF containing CFT, and a single-stage MF containing CFT (Fig. 1). Methanogenesis was inhibited in the BES and NBES by loading the artificial medium at a $\mathrm{pH}$ of 6.5 , which contained glucose as the major carbon source, and the $\mathrm{pH}$ was maintained at $\geq 6.2$ (Table 1 ). The potential of the working electrode in the BES was regulated to $-1.0 \mathrm{~V}$ (vs. $\mathrm{Ag} / \mathrm{AgCl})$. Under standard conditions $\left(25{ }^{\circ} \mathrm{C}\right.$, $\mathrm{pH}=7$ ), hydrogen is formed via electrolysis of water under $-414 \mathrm{mV}$ (vs. the standard hydrogen electrode). However, no abiotic hydrogen production occurred when the less-reactive carbon sheet (i.e., graphite block) was used as the electrode.

The reactor performances were compared after operation for a period more than thrice the HRT (i.e., $12[4 \times 3]$ days) (Fig. 2). The rector performances were similar for the cathodic and anodic sides in the BES; therefore, the average values of the cathodic and anodic sides are explained here for the BES. Inhibition of methanogenesis, based on a lower production of methane and higher production of hydrogen, was clearer in the BES than in the NBES (Fig. 2a), although the methane content in the gas was low in both the BES (7.3\%) and NBES (24.4\%), considering that the methane content was greater than $60 \%$ under stable methane fermentation [12]. The hydrogen contents in the gas were 25.0 and $7.4 \%$, corresponding to low hydrogen yields of $0.42 \mathrm{mM} / \mathrm{mM}_{\text {glucose }}$ and $0.18 \mathrm{mM} /$ $\mathrm{mM}_{\text {glucose }}$ in the BES and NBES, respectively. An average current of $0.88 \mathrm{~A} / \mathrm{m}^{2}$ per electrode was observed, corresponding to hydrogen production of $1.5 \mathrm{mM} /$ day, assuming that all the current is used for hydrogen production. However, the hydrogen production in the BES was greater than that in the NBES by $3.35(=5.85-2.50) \mathrm{mM} /$ 


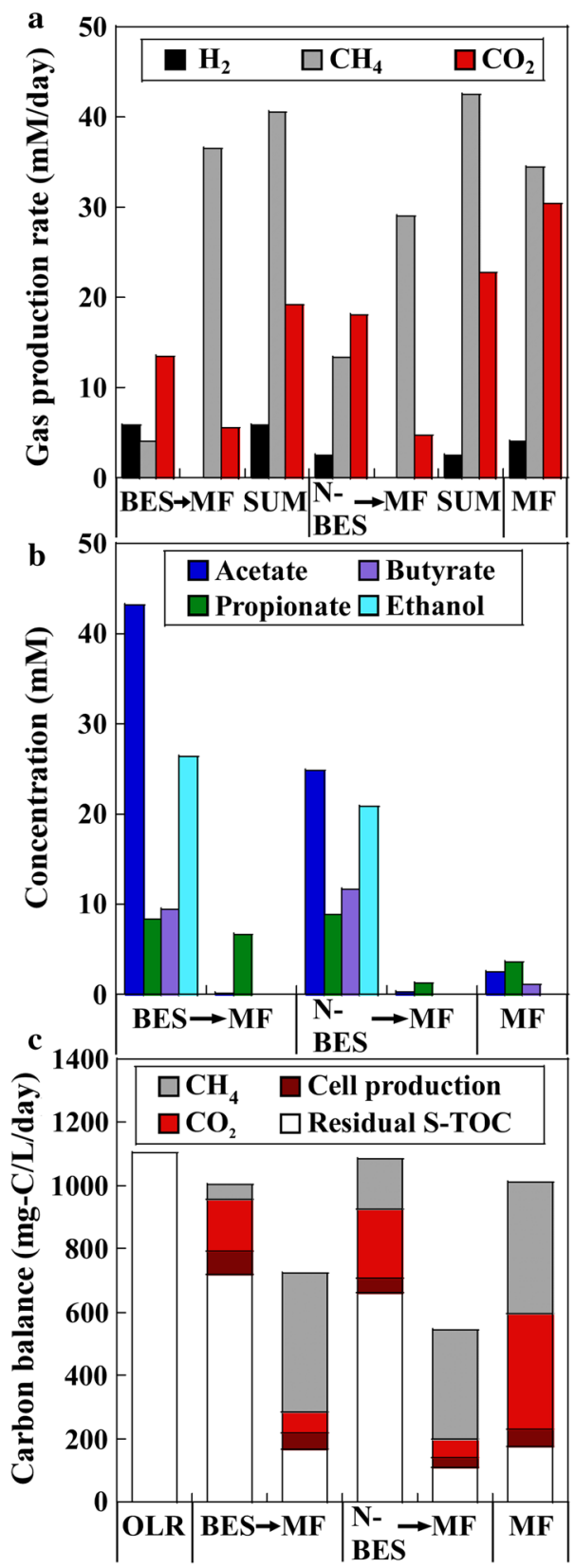

Fig. 2 Reactor performances of the two-stage processes of bioelectrochemical system (BES) $\rightarrow$ methane fermenter (MF) and non-bioelectrochemical system (NBES) $\rightarrow$ methane fermenter (MF), and single-stage process of methane fermenter (MF). a Rate of gas production of hydrogen, methane, and carbon dioxide, $\mathbf{b}$ productions of soluble metabolic products. c Carbon balance of the system. The organic loading rate (OLR) of the BES, NBES, and single-stage MF was $1103.8 \mathrm{mg}-\mathrm{C} / \mathrm{L} /$ day, corresponding to a glucose load of $13.9 \mathrm{mM}_{\text {glucose }} / \mathrm{L} /$ day. The hydraulic retention time (HRT) of all reactors was 4 days day ( $>1.5)$; thus, the reason for increase in hydrogen production was not electrolysis, but rather microbial activity in the BES. Theoretically, acetate and butyrate formation from glucose accompany hydrogen production, although ethanol and propionate are formed from glucose under hydrogen-neutral and hydrogen-consumption pathways, respectively [24, 25]. Accordingly, a greater amount of acetate was generated as part of the soluble metabolic products in the BES than in the NBES, and the amount of propionate and butyrate generated were similar for the BES and NBES (Fig. 2b). By contrast, more ethanol was generated in the BES than in the NBES.

Most of the residual S-TOC in the effluents of the BES and NBES was transformed into methane and carbon dioxide in the subsequent MF that was operated at an HRT of 4 days (Fig. 2c). The methane contents in the gas produced from the MFs after the application of the BES and NBES (86.7 and $85.9 \%$, respectively) were similar and greater than that in the single-stage MF (50.0\%). Thus, as expected, the total amounts of methane and carbon dioxide produced in the two-stage processes $(\mathrm{BES} \rightarrow \mathrm{MF}$ and NBES $\rightarrow$ MF) were higher and lower, respectively, than that in the single-stage MF (Fig. 2a).

\section{Increased methane production in the two-stage process of the BES and MF at a relatively high organic load}

A short HRT (e.g., $0.5 \mathrm{~h}-2$ days) is one of the critical parameters for inhibiting methanogenesis during dark hydrogen fermentation [12]. By shortening the HRT to 2 days at a relatively high OLR of $2207.6 \mathrm{mg}-\mathrm{C} / \mathrm{L} /$ day (Table 1), the effect of electrochemical regulation on the reactor performance was investigated and the reactor performances of the BES and NBES were compared. This OLR corresponded to a glucose load of $27.8 \mathrm{mM}_{\text {glucose }} / \mathrm{L} /$ day. In addition, the reactor performances in the second stage (i.e., MF following BES or NBES) were compared, while the MF was operated at an HRT of 4 days.

A short HRT successfully decreased the methane content in the gas produced from the BES and NBES (0.9 and $0.2 \%$, respectively) (Fig. 3a). Thus, the hydrogen contents of the gas produced from the BES and NBES were increased to 52.1 and $53.2 \%$, respectively. A low average current of $0.30 \mathrm{~A} / \mathrm{m}^{2}$ per electrode in the BES was observed via electrode polarisation, corresponding to a hydrogen production rate of $0.5 \mathrm{mM} /$ day, which was much lower than the actual rate of hydrogen production (i.e., $24.3 \mathrm{mM} /$ day). In contrast to the case of a long HRT of 4 days, the hydrogen yield in the NBES $(1.60 \mathrm{mM} /$ $\left.\mathrm{mM}_{\text {glucose }}\right)$ was higher than in the BES $(0.87 \mathrm{mM} /$ 

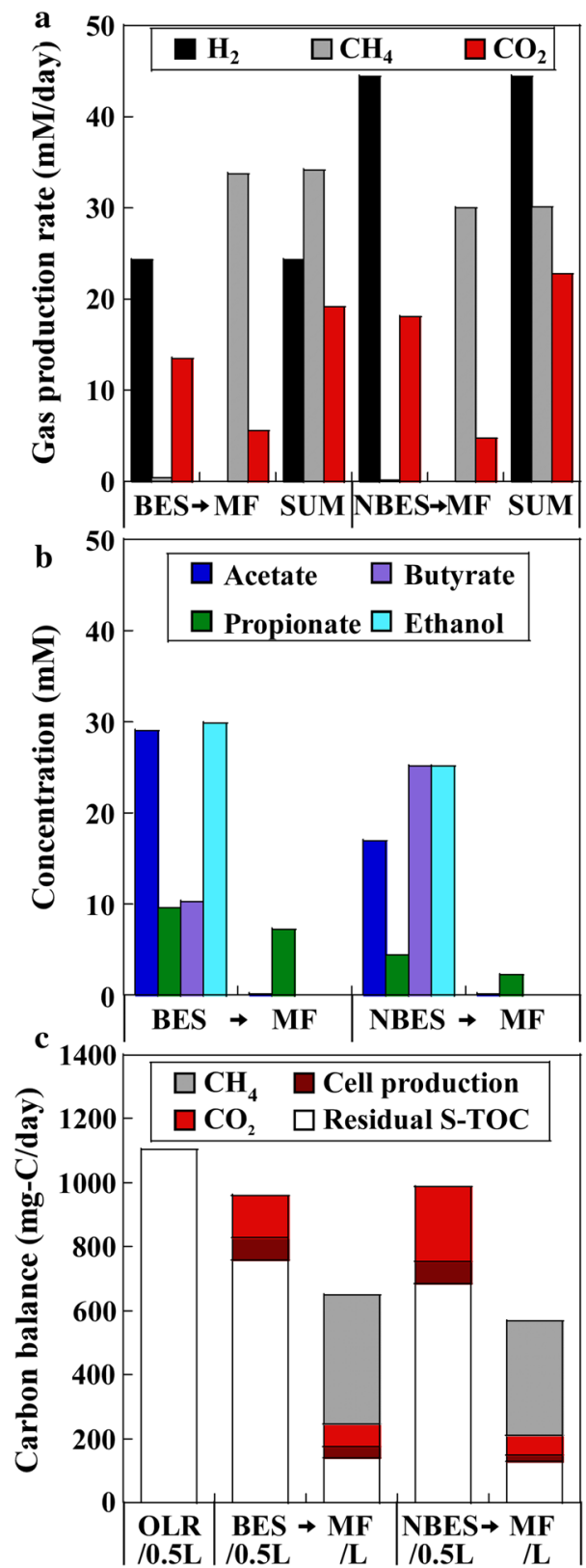

Fig. 3 Reactor performances of two-stage processes of the bioelectrochemical system (BES) $\rightarrow$ methane fermenter (MF) and non-bioelectrochemical system (NBES) $\rightarrow$ MF. a Rate of gas production of hydrogen, methane, and carbon dioxide, $\mathbf{b}$ productions of soluble metabolic products. c Carbon balance of the system. The organic loading rate (OLR) of the BES and NBES was $2207.6 \mathrm{mg}-\mathrm{C} / \mathrm{L} /$ day, corresponding to a glucose load of $27.8 \mathrm{mM}_{\text {glucose }} / \mathrm{L} /$ day. The hydraulic retention time (HRT) of the BES and NBES was 2 days and the HRT of the second-stage MFs was 4 days

$\left.\mathrm{mM}_{\text {glucose }}\right)$. Accordingly, the amount of reduced products, propionate and ethanol produced was higher and that of butyrate generation was lower in the BES than in the NBES, although the amount of acetate generated was higher in the BES than in the NBES (Fig. 3b). Similar to the result at a low OLR, most of the residual S-TOC in the BES and NBES effluents was transformed into methane and carbon dioxide (Fig. 3c). More methane was produced in the MF following the application of the BES than in the MF following the application of the NBES, and the methane contents of the gas were 85.1 and $85.6 \%$ in the MFs following the application of the BES and NBES, respectively. As a result, the amount of methane produced was higher and the amount of hydrogen and carbon dioxide produced was lower in the two-stage $\mathrm{BES} \rightarrow \mathrm{MF}$ process than in the NBES $\rightarrow$ MF process.

A high pH of 7-7.5 in the loaded substrate could optimise hydrogen fermentation in the batch reactors without a regulated $\mathrm{pH}$, as the by-products lower the $\mathrm{pH}$ of the medium [16]. Thus, to eliminate the process of regulating the $\mathrm{pH}$ during the fermentation, an artificial glucose medium at a $\mathrm{pH}$ of 7.3 was loaded in the BES and NBES (Table 1). The other operational parameters were the same as those of the above operation with $\mathrm{pH}$ regulation (6.2-6.5) during fermentation. The results were similar to the results under $\mathrm{pH}$-regulated operation. The hydrogen content in the gas produced from the BES and NBES remained high (47.6 and $47.3 \%$, respectively) (Additional file 1: Fig. S1a). An average current of $0.34 \mathrm{~A} /$ $\mathrm{m}^{2}$ per electrode in the BES corresponded to hydrogen production of $0.6 \mathrm{mM} /$ day, which was much lower than the actual hydrogen production $(16.7 \mathrm{mM} /$ day $)$. The hydrogen yield in the NBES $\left(1.00 \mathrm{mM} / \mathrm{mM}_{\text {glucose }}\right)$ was higher than that in the BES $\left(0.60 \mathrm{mM} / \mathrm{mM}_{\text {glucose }}\right)$. The amount of reduced products, propionate, and ethanol generated was higher and that of butyrate was lower in the BES than in the NBES, although acetate generation was higher in the BES than in the NBES (Additional file 1: Fig. S1b). Most of the residual S-TOC in the effluents of the BES and NBES were transformed into methane and carbon dioxide (Additional file 1: Fig. S1c) and methane production was higher in the MF following the application of the BES (methane content: $86.2 \%$ ) than following the application of NBES (methane content: $86.5 \%$ ). The total amount of methane produced was higher and that of hydrogen and carbon dioxide was lower in the $\mathrm{BES} \rightarrow \mathrm{MF}$ process than in the NBES $\rightarrow$ MF process.

\section{Microbial 16S rRNA gene sequence analysis}

\section{of the microbial consortium in the fermentation cultures}

The microbial compositions developed in the fermentation cultures of the BES, NBES, subsequent MFs $(\leftarrow$ BES and $\leftarrow$ NBES), and single-stage MF were examined. Using a combination of prokaryotic universal primers and a MiSeq platform, an average of $278,989( \pm 107,052)$ reads was obtained for each sequencing reaction (Table 2). The number of OTUs, which can robustly estimates the 


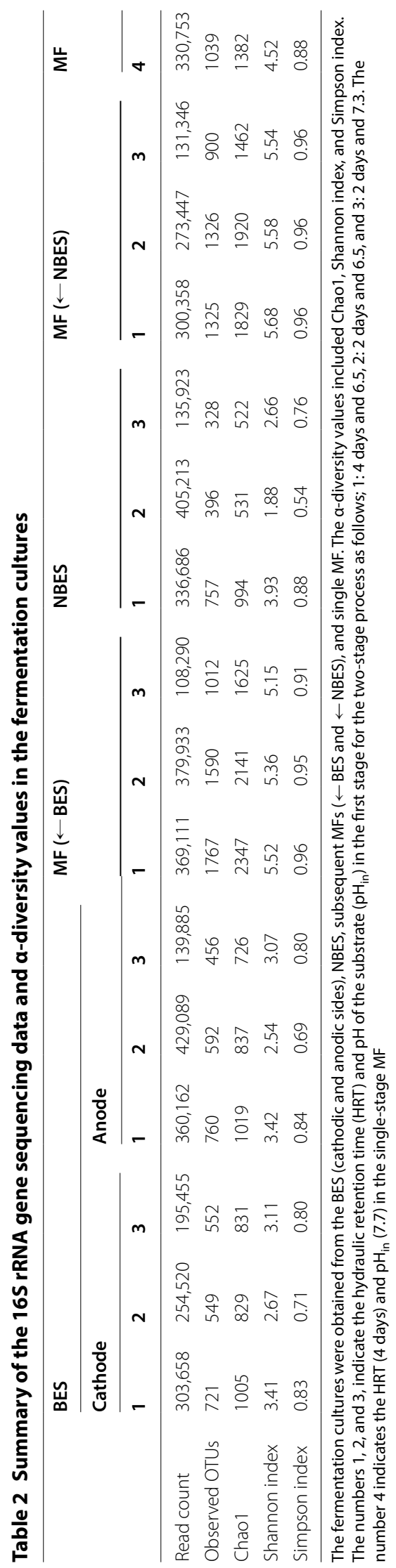


species richness, was lower in the cultures in the first stage (BES or NBES) than in the second stage (MF). The alpha-diversity values ( $\alpha$-diversity; Chao 1 , Shannon index, and Simpson index) are shown in Table 2. The Chao1 values, which indicate the species richness of the community, were lower in cultures of the first stage than in the second stage. Accordingly, the Simpson and Shannon diversity indices, which emphasise the species diversity and evenness of the consortium, were lower in the cultures of the first stage than in those of the second stage. Notably, at a short HRT (2 days) (i.e., high organic load), the number of OTUs and $\alpha$-diversity values were higher in the cultures of the BES than in those of the NBES.

PCoA of unweighted UniFrac distances revealed that the microbial compositions differed between the BES and NBES (Fig. 4). However, the microbial compositions were similar for all MFs. The microbial composition was examined at the genus level (Fig. 5). Most of the microorganisms were assigned to four phyla (Firmicutes, Chloroflexi, Bacteroidetes, and Euryarchaeota) in all reactors. The dominant phylum was Firmicutes in the BES and NBES, consisting of mainly microorganisms belonging to the Clostridium and Thermoanaerobacterium genera, particularly in the NBES. However, the relative abundance of microorganisms belonging to Ruminococcus and uncultured Veillonellaceae were higher on the cathodic and anodic sides of the BES compared to that in the NBES. In all MFs, the relative abundance of microorganisms belonging to methanogens (i.e., the Methanobacterium, Methanothermobacter, and Methanosarcina) increased compared to thoset in the BES and NBES. In addition to methanogens, many bacterial species belonging to uncultured Bacteroidaceae, uncultured Anaerolineaceae, and the Pelotomaculum, Syntrophomonas, and Thermoacetogenium increased in all MFs. The relative abundance of microorganisms belonging to Clostridium increased in the single-stage MF process compared to the secondstage MFs.

\section{Discussion}

Methane production in the second stage was increased owing to a change in the microbial consortium, which was driven by the application of the BES in the first hydrogen fermentation stage due to a change in the microbial consortium. The two-stage process including the BES decreased the total production of carbon dioxide under an HRT of 2 days by lowering the amount of gas in the first stage with a relatively high content of carbon dioxide and increasing the amount of gas in the second stage with a relatively low content of carbon dioxide, which contributed to a decrease in the cost of upgrading biogas to remove carbon dioxide. The number and diversity of microbial species were high owing to the low electric current in the reactor under this HRT condition, although the cell production was similar for the BES and NBES (Fig. 4). High microbial diversities can enhance resistance to environmental stresses, such as high organic loads [26].

During dark hydrogen fermentation, the upper limit of the hydrogen yield of glucose is $4 \mathrm{~mol} \mathrm{H}_{2}$ per mole of hexose during acetic fermentation [Eq. (1)], while $2 \mathrm{~mol}$ $\mathrm{H}_{2}$ per mole of hexose is recorded in the butyrate pathway [Eq. (2)] [16, 25]:

$$
\mathrm{C}_{6} \mathrm{H}_{12} \mathrm{O}_{6}+2 \mathrm{H}_{2} \mathrm{O} \rightarrow 2 \mathrm{CH}_{3} \mathrm{COOH}+2 \mathrm{CO}_{2}+4 \mathrm{H}_{2}
$$

$$
\mathrm{C}_{6} \mathrm{H}_{12} \mathrm{O}_{6} \rightarrow \mathrm{CH}_{3} \mathrm{CH}_{2} \mathrm{CH}_{2} \mathrm{COOH}+2 \mathrm{CO}_{2}+2 \mathrm{H}_{2} \text {. }
$$

Thus, the amount of hydrogen produced as calculated from the concentration of acetate and butyrate in the NBES at an HRT of 2 days with a substrate $\mathrm{pH}_{\text {in }}$ of 6.5 and 7.3 was $42.2 \mathrm{mM}[=2 \times(17 / 2)+2 \times(25.2) / 2]$ and $35.3 \mathrm{mM}$, comparable to the actual hydrogen production of 44.4 and $27.8 \mathrm{mM}$, respectively. However, the actual amount of hydrogen produced, 24.3 and $16.7 \mathrm{mM}$, in the BES was much lower than the values calculated from the acetate and butyrate concentrations, 39.4 and $36.1 \mathrm{mM}$, at an HRT of 2 days with a substrate $\mathrm{pH}_{\text {in }}$ of 6.5 and 7.3, respectively. These results showed that a hydrogen-consumption reaction occured in the BES, although the ratio of hydrogen to carbon dioxide in the gas was unchanged in the BES and NBES. This was also supported by the fact that the hydrogen yield was lower in the BES $(0.60-$ $\left.0.87 \mathrm{mM} / \mathrm{mM}_{\text {glucose }}\right)$ than in the NBES (1.00-1.60 mM/ $\left.\mathrm{mM}_{\text {glucose }}\right)$ at an HRT of 2 days, as the typical hydrogen yield ranges from 1 to $2.5 \mathrm{mM} / \mathrm{mM}_{\text {glucose }}$ [25].

Next, we considered the reason for the low hydrogen yield caused by the low electric current induced by electrode polarisation in the BES operated at an HRT of 2 days. It is reasonable that microorganisms belonging to Bacillus, Clostridium, and Thermoanaerobacterium were dominant in both the BES and NBES, because these organisms include typical anaerobic fermentative bacteria that convert monosaccharides into hydrogen [27-30]. Clostridium and Thermoanaerobacterium are the dominant hydrogen producers during acetate/butyrate fermentation under thermophilic conditions [24,31]; thus, a decrease in these genera corresponds corresponded with decreased butyrate production in the BES. Interestingly, microorganisms belonging to the Ruminococcus species that reportedly produce ethanol in addition to hydrogen and acetic acid [32], increased in the BES. Accordingly, 


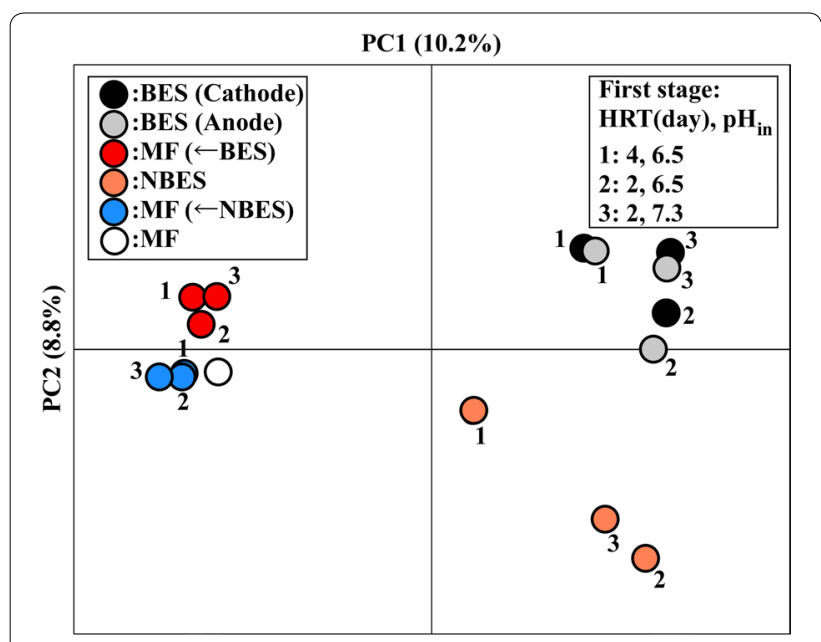

Fig. 4 Principal coordinate plot of the 165 metagenomics data of the microbial species in the fermentation cultures on the cathodic and anodic sides of the bioelectrochemical system (BES), non-bioelectrochemical system (NBES), second-stage methane fermenters (MFs) $(\leftarrow B E S$ and $\leftarrow N B E S)$, and single-stage MF. The numbers indicate the hydraulic retention time (HRT) and $\mathrm{pH}$ of the substrate $\left(\mathrm{pH}_{\text {in }}\right)$ in the first stage for the two-stage process as follows: $1: 4$ days and $6.5,2: 2$ days and 6.5 , and $3: 2$ days and 7.3 this corresponded with increased ethanol production in the BES. Microorganisms belonging to the Veillonellaceae family, which is known to produce propionate as a major fermentation product [33,34], also increased in the BES. This result corresponds with increased propionate production in the BES, which contributes to hydrogen consumption [Eq. (3)]:

$$
\mathrm{C}_{6} \mathrm{H}_{12} \mathrm{O}_{6}+2 \mathrm{H}_{2} \rightarrow 2 \mathrm{CH}_{3} \mathrm{CH}_{2} \mathrm{COOH}+2 \mathrm{H}_{2} \mathrm{O} \text {. }
$$

An increase in volatile fatty acids, except butyrate, led to a decrease in hydrogen production in the BES, whereas acetate production increased. One explanation for the increased acetate production irrespective of the lower hydrogen yield is that an acetogenic hydrogen-consuming reaction, homoacetogenesis [Eq. (4)] [35, 36], may occur in the BES; however, this has not been clarified

$$
2 \mathrm{CO}_{2}+4 \mathrm{H}_{2} \rightarrow \mathrm{CH}_{3} \mathrm{COOH}+2 \mathrm{H}_{2} \mathrm{O} \text {. }
$$

The mechanism of the change in the structure of the microbial community is interesting. Direct electron transfer between the electrode and microorganisms [37] had a low impact in the reactions because of the low

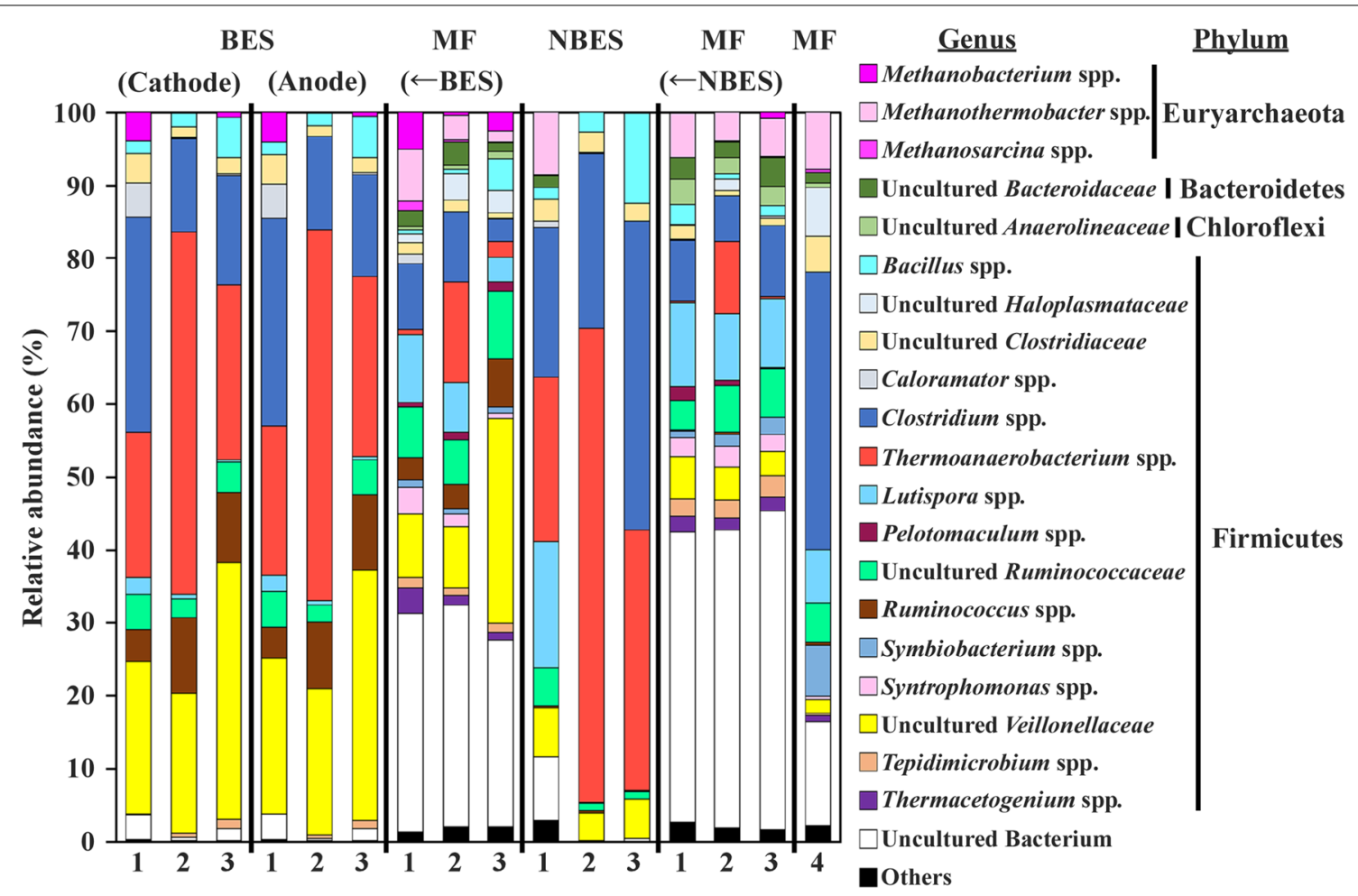

Fig. 5 Genus-level compositional view of the microorganisms in the fermentation cultures on the cathodic and anodic sides of the bioelectrochemical system (BES), non-bioelectrochemical system (NBES), second-stage methane fermenters (MFs) $\leftarrow$ BES and $\leftarrow$ NBES), and single-stage MF. Genera of lower similarity (<97\%) and lower abundance $(<1.0 \%)$ were included under Uncultured Bacteria and Others, respectively. The numbers 1, 2, and 3 indicate the hydraulic retention time (HRT) and $\mathrm{pH}$ of the substrate $\left(\mathrm{pH}_{\mathrm{in}}\right.$ ) in the first stage for the two-stage process as follows: 1: 4 days and 6.5, 2: 2 days and 6.5, and 3: 2 days and 7.3. The number 4 indicates the HRT (4 days) and pH in (7.7) in the single-stage MF 
current density. At an HRT of 4 days, the BES inhibited methanogenic archaea, corresponding to the results of our previous research [15]. Previous studies have shown that the redox potential in the fermentation culture affects the growth of methanogenic archaea [38, 39]. We speculate that a high redox potential owing to the anodic reaction suppressed the growth and/or methanogenesis by methanogenic archaea [15], considering the fact that the redox potential of the anode was $0.85 \mathrm{~V}$ in this study. Villano et al. [40] showed that cathodic reaction increased isobutyrate production in the microbial consortium cultured in the BES with a proton exchange membrane to separate the cathode and anode. Thus, the construction of an environment with different redox potentials in the reactor could change the microbial consortium structure, leading to increased growth of microorganisms related to the Ruminococcus genus and Veillonellaceae family.

The species richness was higher in the second stage (i.e., MF) compared to that in the first stage, probably due to the neutral $\mathrm{pH}$ conditions during methane fermentation. For methanogenesis, hydrogenotrophic methanogens (i.e., Methanobacterium and Methanothermobacter) and acetoclastic methanogen (i.e., Methanosarcina) [12], increased in the MF cultures. It is reasonable that an increase in microorganisms related to Pelotomaculum and Syntrophomonas was observed in the MF cultures, because these microorganisms reportedly grow via syntrophy with methanogens to degrade propionate and butyrate, respectively $[41,42]$. Interestingly, the microbial community structure in the fermentation cultures did not differ significantly between second-stage and singlestage MF, probably due to the retention of major microorganisms in the CFT $[18,43]$.

\section{Conclusions}

We assessed the application of a BES in the first stage of a two-stage process to recover hydrogen and methane using glucose as a model organic substrate. The BES used low-cost carbon sheets and applied electric current that was low enough to prevent water electrolysis by electrode polarisation. The initial $\mathrm{pH}$ in the first stage was relatively high, 6.5 or 7.3, to decrease the cost of lowering the $\mathrm{pH}$. The second stage included CFTs in the reactor for efficient methane generation. The effect of electrode polarisation by the BES on the suppression of methanogenesis was clear at a relatively long HRT. Moreover, the electrode polarisation changed the microbial consortium structure and metabolic patterns. Particularly at a relatively short HRT, the BES increased the species richness of the microbial consortium and the relative abundance of microorganisms related to the Ruminococcus genus and Veillonellaceae family, corresponding to an increase in the generation of ethanol and propionate. A decreased relative amount of microorganisms related to the Clostridium and Thermoanaerobacterium genera corresponded to a decrease in the generation of hydrogen and butyrate in the BES. In addition, a greater amount of acetate was generated in the BES. These changes were likely triggered by changing the redox potential of the electrode; however, future clarification of this mechanism is necessary. The BES reduced the amount of gas produced in first stage and increased the amount produced in the second stage. This resulted in an increase in the generation of methane and decrease in the generation of carbon dioxide in the two-stage process.

\section{Additional file}

Additional file 1: Fig. S1. Reactor performances of the two-stage pro cesses of the bioelectrochemical system (BES) $\rightarrow$ methane fermenter (MF) and non-bioelectrochemical system (NBES) $\rightarrow$ methane fermenter (MF). (a) Rate of gas production of hydrogen, methane, and carbon dioxide. (b) Production of soluble metabolic products. (c) Carbon balance of the system. The organic loading rate (OLR) of the BES and NBES was 2207.6

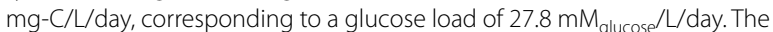
$\mathrm{pH}$ of the substrate was 7.3. The hydraulic retention time (HRT) of the BES and NBES was 2 days and the HRT of second-stage MFs was 4 days.

\section{Abbreviations}

BES: bioelectrochemical system; NBES: non-bioelectrochemical system; MF: methane fermenter; rRNA: ribosomal RNA; OLR: organic loading rate; MEC: microbial electrolysis cell; CFTs: carbon fibre textiles; DSMZ: Deutsche Sammlung von Mikroorganismen und Zellkulturen; HRT: hydraulic retention time; S-TOC: soluble total organic carbon; EDTA: ethylenediaminetetraacetic acid; PCR: polymerase chain reaction; QIIME: Quantitative Insights Into Microbial Ecology; OTU: operational taxonomic unit; RDP: Ribosomal Database Project; PCoA: principal coordinate analysis.

\section{Authors' contributions}

KS designed the research and operated fermenters. YT, MM, and AK evaluated the performances. DS analyzed the microbial consortium structures. KS and YT wrote and reviewed the manuscript. All authors read and approved the final manuscript.

\section{Author details}

${ }^{1}$ Graduate School of Science, Technology and Innovation, Kobe University, 1-1 Rokkodaicho, Nada-ku, Kobe, Hyogo 657-8501, Japan. ${ }^{2}$ Institute for Frontier Science Initiative, Kanazawa University, Kakuma-machi, Kanazawa, Ishikawa 920-1192, Japan. ${ }^{3}$ Environmental Chemistry Sector, Environmental Science Research Laboratory, Central Research Institute of Electric Power Industry, 1646 Abiko, Abiko-shi, Chiba-ken 270-1194, Japan. ${ }^{4}$ RIKEN Center for Sustainable Resource Science, 1-7-22 Suehiro-cho, Tsurumi-ku, Yokohama, Kanagawa 230-0045, Japan.

\section{Acknowledgements}

We are grateful to Ayami Fujino, Shoko Sakai, Yasuko Koura, and Yasunobu Takeshima (Kobe University) for their help.

\section{Competing interests}

The authors declare that they have no competing interests.

\section{Availability of data and materials}

The sequencing data are stored in MG-RAST under the Accession Numbers mgm4779451.3-mgm4779466.3.

Consent for publication

Not applicable. 
Ethics approval and consent to participate Not applicable.

\section{Funding}

This work was supported by the Special Coordination Fund for Promoting Science and Technology, Creation of Innovative Centers for Advanced Interdisciplinary Research Areas (Innovative Bioproduction, Kobe), and the Ministry of Education, Culture, Sports, Science, and Technology (MEXT), Japan. This work was also partly supported to KS from Osaka Gas Co., Ltd., Japan.

\section{Publisher's Note}

Springer Nature remains neutral with regard to jurisdictional claims in published maps and institutional affiliations.

\section{Received: 14 February 2018 Accepted: 15 June 2018}

Published online: 22 June 2018

\section{References}

1. Sasaki K, Sasaki D, Kamiya K, Nakanishi S, Kondo A, Kato S. Electrochemical biotechnologies minimizing the required electrode assemblies. Curr Opin Biotechnol. 2018;50:182-8.

2. Schievano A, Pepé Sciarria T, Vanbroekhoven K, De Wever H, Puig S, Andersen SJ, Rabaey K, Pant D. Electo-fermentation - merging electrochemistry with fermentation in industrial applications. Trends Biotechnol. 2016:34:866-78.

3. Kracke F, Vassilev I, Krömer JO. Microbial electron transport and energy conservation - the foundation for optimizing bioelectrochemical systems. Front Microbiol. 2015:6:575

4. Moscoviz R, Toledo-Alarcón J, Trably E, Bernet N. Electro-fermentation: how to drive fermentation using electrochemical systems. Trends Biotechnol. 2016;34:856-65.

5. Marshall CW, LaBelle EV, May HD. Production of fuels and chemicals from waste by microbiomes. Curr Opin Biotechnol. 2013;24:391-7.

6. Ward AJ, Hobbs PJ, Holliman PJ, Jones DL. Optimisation of the anaerobic digestion of agridultural resources. Bioresour Technol. 2008;99:7928-40.

7. Sasaki K, Morita M, Matsumoto N, Sasaki D, Hirano S, Ohmura N, Igarashi Y. Construction of hydrogen fermentation from garbage slurry using the membrane free bioelectrochemical system. J Biosci Bioeng. 2012;114:64-9.

8. Hussain A, Lebrun FM, Tartakovsky B. Removal of organic carbon and nitrogen in a membraneless flow-through microbial electrolysis cell. Enzyme Microb Technol. 2017:102:41-8.

9. Gao Y, Sun D, Dang Y, Lei Y, Ji J, Lv T, Bian R, Xiao Z, Yan L, Holmes DE. Enhancing biomethanogenic treatment of fresh incineration leachate using single chambered microbial electrolysis cells. Bioresour Technol. 2017;231:129-37.

10. Sasaki K, Sasaki D, Morita M, Hirano S, Matsumoto N, Ohumura N, Igarashi Y. Bioelectrochemical system stabilizes methane fermentation from garbage slurry. Bioresour Technol. 2010;110:3415-22.

11. Liu W, He Z, Yang C, Zhou A, Guo Z, Liang B, Varrone C, Wang AJ. Microbial network for waste activated sludge cascade utilization in an integrated system of microbial electrolysis and anaerobic fermentation. Biotechnol Biofuels. 2016;9:83

12. Xia A, Chen J, Murphy JD. Innovation in biological production and upgrading of methane and hydrogen for use as gaseous transport biofuel. Biotechnol Adv. 2016:34:451-72

13. Gómez X, Fernández C, Fierro J, Sánchez ME, Escapa A, Morán A. Hydrogen production: two stage processes for waste degradation. Bioresour Technol. 2011;102:8621-7.

14. Call D, Logan BE. Hydrogen production in a single chamber microbial electrolysis cell lacking a membrane. Environ Sci Technol. 2008;42:3401-6.

15. Sasaki K, Morita M, Sasaki D, Ohmura N, Igarashi Y. The membraneless bioelectrochemical reactor stimulates hydrogen fermentation by inhibiting methanogenic archaea. Appl Microbiol Biotechnol. 2013;97:7005-13.

16. Guo XM, Trably E, Larille E, Carrére H, Steyer JP. Hydrogen production from agricultural waste by dark fermentation: a review. Int J Hydrogen Energ. 2010:35:10660-73.

17. Zhao Z, Zhang Y, Wang L, Quan X. Potential for direct interspecies electron transfer in an electric-anaerobic system to increase methane production from sludge digestion. Sci Rep. 2015;5:11094.
18. Sasaki K, Morita M, Hirano S, Ohmura N, Igarashi Y. Decreasing ammonia inhibition in thermophilic bioreactors using carbon fiber textiles. Appl Microbiol Biotechnol. 2011;90:1555-61.

19. Hoover SR, Porges N. Assimilation of dairy wastes by activated sludge: II. The equation of synthesis and rate of oxygen utilization. Sewage Ind Wastes. 1952;24:306-12.

20. Takahashi S, Tomita J, Nishioka K, Hisada T, Nishijima M. Developmentof a prokaryotic universal primer for simultaneous analysis of Bacteria and Archaea using next-generation sequencing. PLoS ONE. 2014;9:e105592.

21. Caporaso JG, Kuczynski J, Stombaugh J, Bittinger K, Bushman FD, Costello EK, et al. QIIME allows analysis of high-throughput community sequencing data. Nat Methods. 2010;7:335-6.

22. Edgar RC. Search and clustering orders of magnitude faster than BLAST. Bioinformatics. 2010;26:2460-1.

23. Wang Q, Garrity GM, Tiedje JM, Cole JR. Naïve Bayesian classifier for rapid assignment of rRNA sequences into the new bacterial taxonomy. Appl Environ Microbiol. 2007;73:5261-7.

24. Lee HS, Vermaas WFJ, Rittman BE. Biological hydrogen production: prospects and challenges. Trends Biotechnol. 2010;28:262-71.

25. Angenent LT, Karim K, Al-Dahhan MH, Wrenn BA, Domíquez-Espinosa R Production of bioenergy and biochemical from industrial and agricultural wastewater. Trends Biotechnol. 2004:22:477-85.

26. Zhang J, Zhang Y, Quan X, Chen S. Effect of ferric iron on the anaerobic treatment and microbial diversity in a coupled microbial electrolysis cell (MEC) —anaerobic reactor. Water Res. 2013;47:5719-28.

27. Zhang F, Yang JH, Dai K, Chen Y, Li QR, Gao FM, Zeng RJ. Characterization of microbial compositions in a thermophilic chemostat of mixed culture fermentation. Appl Microbiol Biotechnol. 2016;100:1511-21.

28. Zheng HS, Guo WQ, Yang SS, Feng XC, Du JS, Zhou XJ, Chang JS, Ren NQ Thermophilic hydrogen production from sludge pretreated by thermophilic bacteria: analysis of the advantages of microbial community and metabolism. Bioresour Technol. 2014;172:433-7.

29. Ueno Y, Fukui $\mathrm{H}$, Goto M. Operation of a two-stage fermentation process producing hydrogen and methane from organic waste. Environ Sci Technol. 2007:41:1413-9.

30. Levin DB, Pitt L, Love M. Biohydrogen production: prospects and limitations to practical application. Int J Hydrogen Energy. 2004;29:173-85.

31. O-Thong S, Prasertsan P, Birkeland NK. Evaluation of methods for preparing hydrogen-producing seed inocula under thermophilic condition by process performance and microbial community analysis. Bioresour Technol. 2009;100:909-18.

32. Ntaikou I, Gavala HN, Kornaros M, Lyberatos G. Hydrogen production from sugars and sweet sorghum biomass using Ruminococcus albus. Int J Hydrogen Energy. 2008;33:1153-63.

33. Louis P, Flint HJ. Formation of propionate and butyrate by the human gut colonic microbiota. Environ Microbiol. 2017;19:29-41.

34. Kishimoto A, Uchida K, Phillips GO, Ogasawara T, Sasaki Y. Identification of intestinal bacteria responsible for fermentation of gum Arabic in pig model. Curr Microbiol. 2006:53:173-7.

35. Parameswaran P, Torres Cl, Lee HS, Rittman BE, Krajmalnik-Brown R. Hydrogen consumption in microbial electorchemical systems (MXCs): the role of homo-acetogenic bacteria. Bioresour Technol. 2011;102:263-71.

36. Yun YM, Lee MK, Im SW, Marone A, Trably E, Shin SR, Kim MG, Cho SK, Kim $\mathrm{DH}$. Biohydrogen production from food waste: current status, limitations, and future perspectives. Bioresour Technol. 2018:248:79-87.

37. Lovley DR. Powering microbes with electricity: direct electron transfer from electrodes to microbes. Environ Microbiol Rep. 2011:3:27-35.

38. Hirano S, Matsumoto N, Morita M, Sasaki K, Ohmura N. Electrochemical control of redox potential affects methanogenesis of the hydrogenotrophic methanogen Methanothermobacter thermautotrophicus. Lett Appl Microbiol. 2013;56:315-21.

39. Sasaki D, Sasaki K, Morita M, Hirano S, Matsumoto N, Ohmura N. Bioelectrochemical regulation accelerates facultatively syntrophic proteolysis. J Biosci Bioeng. 2012:114:59-63.

40. Villano M, Painano P, Palma E, Miccheli A, Majone M. Electrochemically driven fermentation of organic substrates with undefined mixed microbial cultures. Chemsuschem. 2017;10:3091-7.

41. Salvador AF, Martins G, Melle-Franco M, Serpa R, Stams AJM, Cavaleiro AJ, Pereira MA, Alves MM. Carbon nanotubes accelerate methane production 
in pure cultures of methanogens and in a synrophic coculture. Environ Microbiol. 2017;19:2727-39.

42. Stams AJ, Plugge CM. Electron transfer in syntrophic communities of anaerobic bacteria and archaea. Nat Rev Microbiol. 2009;7:568-77.
43. Sasaki D, Sasaki K, Watanabe A, Morita M, Matsumoto N, Igarashi Y, Ohmura N. Operation of a cylindrical bioelectrochemical reactor containing carbon fiber fabric for efficient methane fermentation from thickened sewage sludge. Bioresour Technol. 2013;129:366-73.
Ready to submit your research? Choose BMC and benefit from:

- fast, convenient online submission

- thorough peer review by experienced researchers in your field

- rapid publication on acceptance

- support for research data, including large and complex data types

- gold Open Access which fosters wider collaboration and increased citations

- maximum visibility for your research: over 100M website views per year

At BMC, research is always in progress.

Learn more biomedcentral.com/submissions 